\title{
USE OF PHOTOBIOMODULATION THERAPY FOR THE EVOLUTION OF IMMUNOMODULATORY MARKERS AND PHYSIOLOGICAL PARAMETERS IN PATIENTS WITH COVID-19
}

\section{Fábio Luiz Costa Pereira' ${ }^{1,2 *}$, Eduardo Luchi ${ }^{2,3}$, José Marcelo Corassa ${ }^{2}$, Fabrício Machado Rossi, ${ }^{1,2}$, Pablo da Silva Mendes, ${ }^{1,2}$, Eduardo Alberto de Castro Roque ${ }^{2}$, Jéssica Soares Caliari², Valéria Salazar Pedrazas ${ }^{2}$, Victor Sales Pereira ${ }^{4}$, Renato Matos Carvalho Fonseca ${ }^{4}$, Bruno Henrique de Castro Evaldt ${ }^{5}$, Gutenberg do Amaral Gurgel ${ }^{6}$ and Rosane Pereira dos Reis ${ }^{7}$}

${ }^{1}$ Instituto Capixaba de Angiologia (ICA); ${ }^{2}$ Hospital Meridional Serra; ${ }^{3}$ Escola Superior de Ciências da Santa Casa de Misericórdia de Vitória (EMESCAM); ${ }^{4}$ Universidade de Vila Velha (UVV); 5 Universidade Federal do Espírito Santo (Ufes); ${ }^{6}$ Professor da Universidade Potiguar e Diretor Hospital Angiovascular; ${ }^{7}$ Universidade Federal de Alagoas (UFAL)

\section{ARTICLE INFO}

Article History:

Received $17^{\text {th }}$ February, 2021

Received in revised form

$28^{\text {th }}$ March, 2021

Accepted $07^{\text {th }}$ April, 2021

Published online $30^{\text {th }}$ May, 2021

\section{Key Words:}

High-intensity laser; Coronavirus; SARS-CoV-2; Photobiomodulation.

*Corresponding autho:

Fábio Luiz Costa Pereira,

\begin{abstract}
The study aimed to evaluate the effectiveness of laser therapy for the evolution of immunomodulatory markers and physiological parameters in patients with COVID-19 with moderate to high risk of death. Twenty seriously diagnosed patients with COVID-19 were selected for the study, which were divided into two groups: control (who did not receive the treatment) and laser (who received the treatment), selected through non-blind randomization. The laser was administered in five areas: pulmonary area, face, tonsillar fossae, trachea, and bronchi. The treatment was monitored throughout its duration, six days. Laboratory tests were collected daily in both groups and several parameters were measured. We tested the difference between the days with paired tests and tested the correlation of the parameters with time using Pearson's correlation. In the laser group, patients showed a constant improvement in partial arterial oxygen pressure $(\mathrm{PaO} 2)$ when compared to patients in the control group. Therefore, when thinking about intervening in the pathophysiology of the disease, one should take into account the use of techniques or drugs that can act both in restricting the most pernicious phase of the inflammatory cascade and in modulating all events related to the evolution of COVID- 19.
\end{abstract}

Copyright (C) 2021, Fábio Luiz Costa Pereira, et al. This is an open access article distributed under the Creative Commons Attribution License, which permits unrestricted use, distribution, and reproduction in any medium, provided the original work is properly cited.

Citation: Fábio Luiz Costa Pereira, Eduardo Luchi, José Marcelo Corassa, Fabrício Machado Rossi, Pablo da Silva Mendes, Eduardo Alberto de Castro Roque, Jéssica Soares Caliari, Valéria Salazar Pedrazas, Victor Sales Pereira, Renato Matos Carvalho Fonseca, Bruno Henrique de Castro Evaldt, Gutenberg do Amaral Gurgel and Rosane Pereira dos Reis, 2021. "Use of photobiomodulation therapy for the evolution of immunomodulatory markers and physiological parameters in patients with Covid-19”, International Journal of Development Research, 11, (05), $47152-47157$.

\section{INTRODUCTION}

In December 2019, several patients with severe pneumonia were identified in Wuhan, Hubei province, China. Subsequently, COVID19 was assigned to a new beta coronavirus, responsible for the severe acute respiratory syndrome by SARS-CoV-2 (1,2). Approximately $20 \%$ of patients diagnosed with COVID-19 develop severe forms of the disease, including acute hypoxemic respiratory failure or severe acute respiratory syndrome, acute renal failure, and thromboembolic phenomena, and require admission to the intensive care unit (ICU). As of the time of this publication, the only clinical trials that have shown a reduction in important adverse events were those performed in critically ill patients using corticosteroids and prophylactic use through vaccination (3). Infection with SARS-CoV-2 has so far caused more than 119 million cases and more than 2 million and 600 thousand confirmed deaths, as of March 15, 2021 (4).
Although there is no solid evidence regarding drugs to prevent or treat SARS-CoV-2 infection, small studies have suggested that the combination of a relative immunosuppression related to lymphopenia are important prognostic factors, which implies the search for modulation of the inflammatory condition and infectious as the basis for a change in the course of the disease $(5,6)$. Currently, we know that the pathophysiology of pneumonia by Sars-Cov-2 involves factors related to increased permeability of the vascular endothelium and its consequent generation of inflammation of the lung parenchyma. More specifically, we can say that the ventilation/ perfusion coefficient in COVID-19 can vary from patient to patient, and even in a single patient, where it is possible to observe pulmonary segments with perfusion and ventilatory impairment at different levels (7). This information can be valuable, denoting from a likely greater difficulty in treating the disease (since its pathophysiological characteristic involves several factors of high complexity) to a greater number of possibilities for plausible 
therapeutic proposals. Intervening in the pathophysiological process of COVID-19 can be a particularly interesting strategy, especially if we consider that antiviral treatments to date have not produced an effective change in the course of the disease. And the already existing and well-established intensive support intervention, such as oxygen therapy, mechanical ventilation, and the use of vasoactive drugs, is very important to keep the patient alive with the best possible functional condition, but it does not act directly on the pathophysiological mechanisms of the disease. Among the possibilities of intervening in this immunomodulation scenario, photobiomodulation using laser application seems promising given the previously known response in the treatment of skin, ophthalmic and dental injuries (8-10). High-intensity lasers are a safe, noninvasive technology approved by both the Food and Drug Administration (FDA) and Health Canada for various chronic and degenerative conditions, temporary pain relief, cellulite treatment, body aesthetics, reduction of lymphedema, growth hair loss, and chronic musculoskeletal injuries. Laser therapy is an accessible modality compared to other treatments and medications such as IL-6 antagonists. It is a safe, effective, and low-cost modality, with no associated inputs or even physical contact with the patient and without any reported side effects compared to other approaches. A laser machine costs about $\$ 40,000$ and each machine can fully treat more than 50,000 patients for COVID-19. In comparison, an IL-6 antagonist costs $\$ 1,000$ per vial, and each patient may need eight doses for the complete treatment of COVID-19. Well-planned laser therapy, combined with standard medical care, can optimize response to treatments, reduce inflammation, promote healing and accelerate patients' recovery times. With this, it could be added to the conventional treatment of COVID-19 at different stages of the disease and can reduce the need for ventilators in the healing process. We aimed to provide a pilot study to evaluate the effectiveness of laser therapy for the evolution of immunomodulatory markers and physiological parameters in patients with COVID-19 with moderate to high risk of death.

\section{METHODS}

Study population: The patients eligible for the study were seriously ill patients diagnosed with COVID- 19 admitted to the Therapy Unit of Hospital Meridional Serra (Serra-ES, Brazil). Inclusion criteria were patients older than 18 years with positive RT-PCR for SarsCov-2; with pulmonary involvement with a TSS score greater than or equal to five points; respiratory dysfunction characterized by the need for at least $11 / \mathrm{min}$ of supplemental oxygen; absence of the need to use invasive mechanical ventilation through orotracheal intubation and patients capable of performing self-prone. The exclusion criteria were: patients in palliative care, with severe autoimmune disease, pregnant women, and those who refused to sign the Informed Consent Form (ICF). The patients were interviewed and duly informed about the technique, risks, and expected benefits, as well as the possibility of not receiving the application of the technique due to the randomization between the control group and the laser group (who received the treatment). Registration started in December 2020 and was completed in February 2021. The approach to patients was conducted following the provisions of the Declaration of Helsinki and the guidelines organized by the International Conference on Good Clinical Practice. Patients were included after signing the informed consent form, or when personal signature is not possible, by a guardian over 18 years of age capable of assuming this commitment. A total of 32 patients were interviewed, however, only 20 patients accepted the terms provided in the consent form. The patients were randomized in a parallel and non-blind manner, with 10 patients in the control group and 10 patients in the laser group. We didn't calculate the ideal sample size because this a pilot study, therefore, we used a small sample size. The essay designed by the researchers had no influence from sponsors on the design of the study.

Treatment protocol: The laser treatment protocol was administered by a physician trained in high-intensity laser therapy (HIL) in the following regions: pulmonary, face (paranasal sinuses and nasal cavity), tonsillar fossae, trachea, and bronchi (Figure 1). The applications were daily, performed on four consecutive days, and uninterrupted. The application is made at a distance, without physical contact between the applicator and the patient, and there was no unpleasant sensation perceived by the patient and referred to the team. The patients were evaluated for six consecutive days from the first day of application of the treatment, thus, all had a follow-up time for data collection, with the stratification of results limited to this period of treatment. The Therapy Laser System model BTL-6000 HighIntensity Laser $10 \mathrm{~W}$ was used, with registration number with ANVISA 80991690011, authorization 8099169, process 25351.428880 / 2019-44 valid until August 12, 2029.

We use the formula: $\mathrm{DE}=(\mathrm{P} x) / \mathrm{A}$; where $\mathrm{DE}=$ energy density $(\mathrm{J}$ $/ \mathrm{cm} 2), \mathrm{P}=$ Power $(\mathrm{Watt}), \mathrm{t}=$ exposure time (seconds), and $\mathrm{A}=$ Laser focus area $\left(\mathrm{cm}^{2}\right)$ to calculate the laser energy density to be applied in the tissues. The Arndt-Schultz Act is considered the standard for describing the dose-dependent effects of laser therapy. The effective stimulation dose of laser therapy is 1 to $10 \mathrm{~J} / \mathrm{cm}^{2}$ in the target tissue. Doses greater than $16 \mathrm{~J} / \mathrm{cm}^{2}$ produce inhibitory effects. The inhibitory effects are used in conditions that require inhibition and suppression of the tissue response (11). Thus, laser dosages favorable to healing are found between energy densities of 1 to $15 \mathrm{~J} / \mathrm{cm}^{2}$, which in turn does not depend on the intensity of the nominal energy used, but rather on the way it interacts with the tissues and the dose. effectively distributed.

For the pulmonary region (each of the lungs): the patients were placed in the prone position in the horizontal prone position. For six minutes, we used an irradiation field (for the laser) $15 \mathrm{~cm}$ wide by 30 $\mathrm{cm}$ high with an energy density of $8 \mathrm{~J} / \mathrm{cm}^{2}$ in automatic continuous mode applied by the scanner system $45 \mathrm{~cm}$ away from the patient's skin. The total treatment time in the pulmonary area was 12 minutes, at $900 \mathrm{~cm}^{2}$ and $7200 \mathrm{~J}$ of energy.

For application in the face region (paranasal sinuses and nasal cavity): patients were placed in the supine position. We used an irradiation field of $8 \mathrm{~cm}$ wide by $5 \mathrm{~cm}$ high for 32 seconds with an energy density of $8 \mathrm{~J} / \mathrm{cm}^{2}$ in manual continuous mode (hand applicator) at a distance of $2 \mathrm{~cm}$ from the skin, totaling $40 \mathrm{~cm}^{2}$ and 320 J. For application in tonsillar fossae (on each side): patients were placed in the horizontal supine position. For 16 seconds, we used an irradiation field $5 \mathrm{~cm}$ wide by $4 \mathrm{~cm}$ high with an energy density of $8 \mathrm{~J}$ $/ \mathrm{cm}^{2}$ in manual continuous mode (hand applicator) at a distance of 2 $\mathrm{cm}$ from the skin, totaling 32 seconds, $40 \mathrm{~cm}^{2}$ and $320 \mathrm{~J}$.

For the trachea and bronchi region: patients were placed in the horizontal supine position. We used an irradiation field $10 \mathrm{~cm}$ wide by $15 \mathrm{~cm}$ with height in the anterior cervical and anterior central thoracic region for two minutes, with an energy density of $8 \mathrm{~J} / \mathrm{cm}^{2}$ in manual continuous mode (hand applicator) at a distance of $2 \mathrm{~cm}$ from the skin, totaling $150 \mathrm{~cm}^{2}$ and $1200 \mathrm{~J}$. Considering all treated regions, the total treatment time was 15:04 min, the total area was $1130 \mathrm{~cm}^{2}$ and the total energy was $9040 \mathrm{~J}$.

Parameters evaluated: Laboratory tests were collected daily in both groups, control and laser, and sent to Metrolab (clinical analysis laboratory) located at the Hospital Meridional Serra. Blood values were measured for: albumin, direct bilirubin, serum bicarbonate, total bilirubin, creatinine, D- dimer, fibrinogen, hematocrit, hemoglobin, lactate, lactate dehydrogenase, leukocytes, magnesium, $\mathrm{pH}$, platelets, potassium, partial pressure of carbon dioxide, partial pressure of oxygen, C-reactive protein, transferrin saturation, sodium, prothrombin time, troponin and urea. Albumin, direct bilirubin, total bilirubin, D-dimer, fibrinogen, lactate, prothrombin time, and troponin were removed from the analysis as they did not have at least 3 samples on any given day.

Statistical analysis: We tested whether there were significant differences in the parameters evaluated between the treatment days in each group. For this, we tested the normality of each variable with the Shapiro-Wilk test and evaluation of the QQ graph, to define whether 
the test to be used to test the difference between the days was paired $t$ test (parametric test) or Wilcoxon test (non-parametric test). We used Pearson's correlation to assess whether there was any linear correlation between treatment time and the parameters evaluated. All analyzes were performed in the $\mathrm{R}$ version 4.0.3 environment using the rstatix 0.6.0 package.

\section{RESULTS}

The following results are only from the analyzes with parameters that showed some significant difference. The laser group had higher averages in the levels of C-reactive protein (CRP) compared to the control group throughout the treatment, with a decrease in the level of the marker in stage 2, stability between stages 2 and 4, and a decrease in stage 5 followed by stability in stage 6 . In the control group, a decrease in the values of the CRP level can be observed throughout the treatment (Fig 2A). There was no significant difference between any of the stages in any of the groups. The correlation test indicated a weak negative correlation between the time of treatment and the level of CRP in the control group $(r=-0.3)$ and in the laser group $(r=-$ $0.13)$, this relationship being significant only in the control group $(p=$ 0.02 ) (Fig. 3A).
Regarding the partial pressure of oxygen, the control group showed an increase in the level of partial pressure of oxygen (PO2) between stages 1 and 2, but then the values fluctuated during the other stages, while the laser group showed constant improvement at the level of $\mathrm{PO} 2$, mainly between stages 4,5 and 6 , although there is no significant difference between any of the stages in the two groups (Fig 2B). The correlation test indicated a weak positive correlation between the time of treatment and the level of PO 2 in the control group $(r=$ $0.16)$ and in the laser group $(r=0.32)$, this relationship is significant only in the laser group $(\mathrm{p}=0.015)$ (Fig. 3B). Both groups showed similar behavior of increasing the level of platelets between stages 1 and 4 , followed by stability between stages 5 and 6 , with the levels of platelets in the initial stages being lower in the laser group. This is reflected in the significant difference between stages 1 to stages 3,4 , 5 , and 6 , and stage 2 to stages 4 and 5 in the laser group, with no significant differences in the control group (Fig 2C). The correlation test indicated a weak non- significant positive correlation between treatment time and platelet level in the control group $(\mathrm{r}=0.25, \mathrm{p}=$ $0.057)$, and a significant weak positive correlation in the laser group $(\mathrm{r}=0.42, \mathrm{p}=0.00089)$ (Fig. 3C). Concerning the level of urea, in the control group, a decrease can be observed between stages 1 and 3, followed by an increase between stages 3 and 6 .
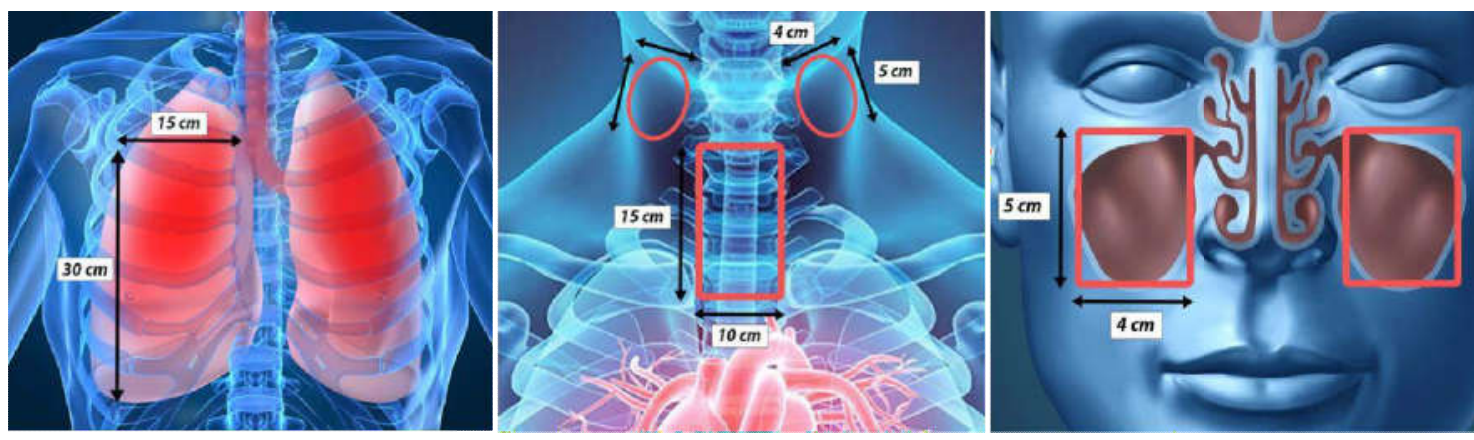

Figure 1. Areas of application of high-intensity laser. Pulmonary region on the left, tonsillar fossae and trachea in the middle, and facial region (paranasal sinuses and nasal cavity) on the right
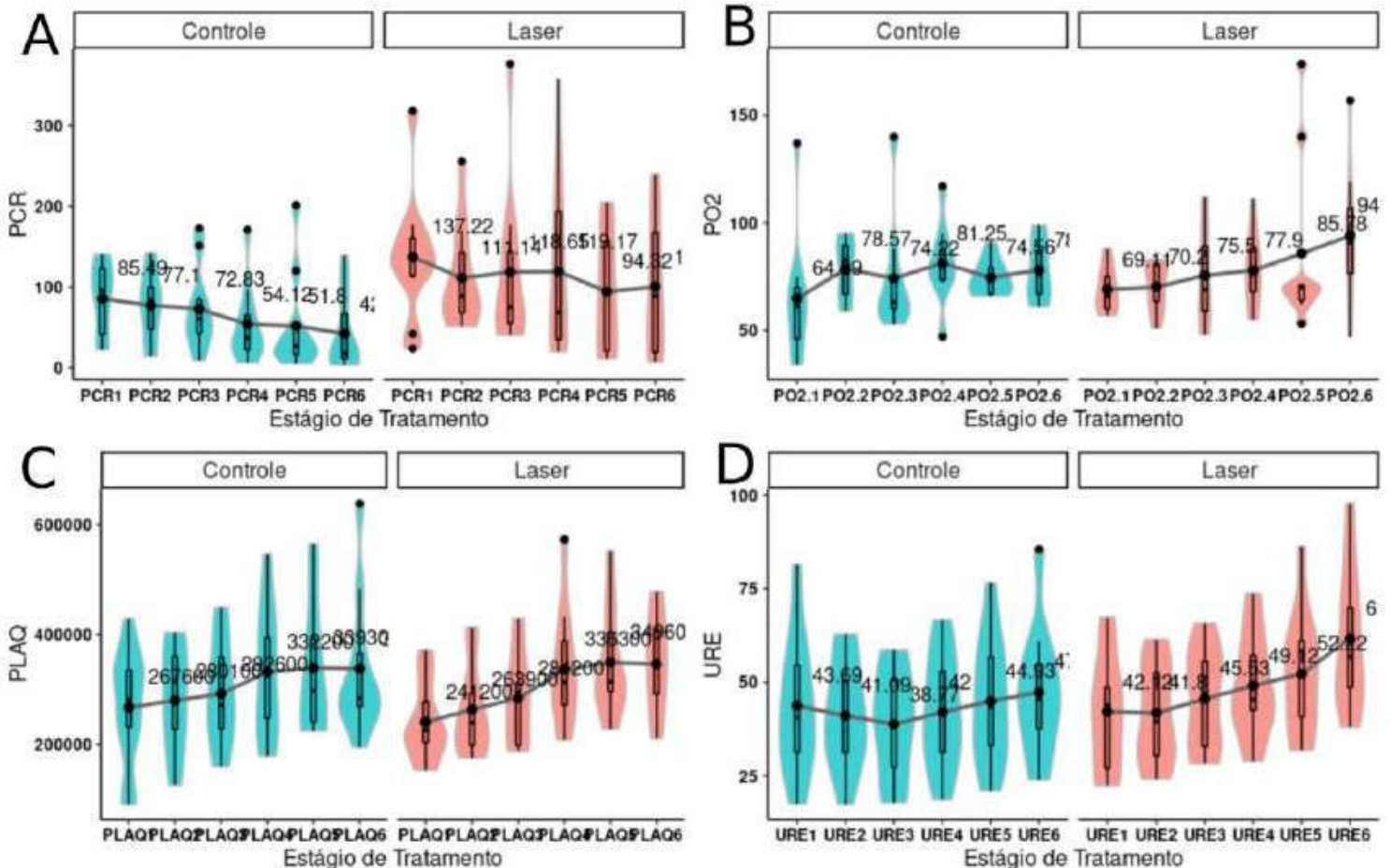

Figure 2. Boxplot graph (darker part) and violin graph (lighter part) indicating the distribution of the parameters evaluated in patients in the control group (left) and the laser group (right) during the treatment stages. A) Reactive Protein C B) Oxygen partial pressure C) Platelets D) Urea. The $\mathrm{X}$-axis represents the treatment stages, from the initial stage on the left to the final stage on the right, and the $\mathrm{Y}$ axis shows the observed values of the parameter. The points connected by the line and the number indicate the mean and the dash indicates the median of the data at each stage of treatment 
In the laser group, the level of urea remained stable between stages 1 and 2 , followed by an increase until stage 6 , reaching higher levels than the control group (Fig 2D). There was no significant difference between any of the stages in the two groups. The correlation test indicated a weak non-significant positive correlation between treatment time and urea level for the control group $(\mathrm{r}=0.1, \mathrm{p}=0.44)$ and a significant weak positive correlation for the laser group $(\mathrm{r}=$ $0.39, \mathrm{p}=0.0023)$ (Fig. 3D).
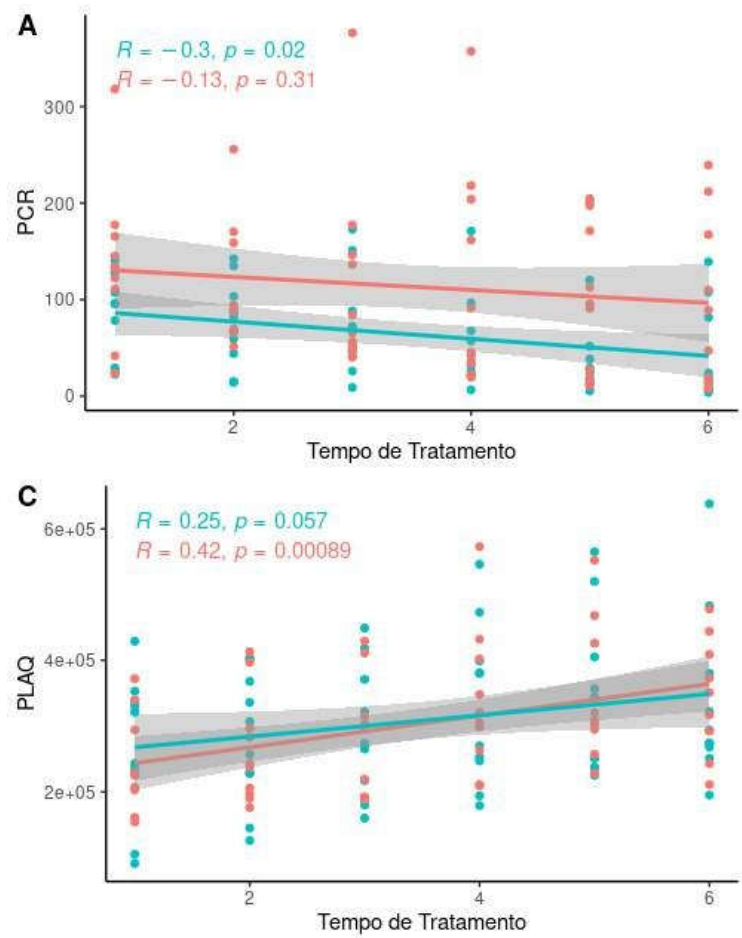

Empirical practice in more than 1000 patients has produced data relating to chronic pneumonia, acute pneumonia, asthma, and chronic bronchitis in children, adults, and the elderly. Common findings include reduced chest pain, weight reduction; normalization of respiratory function; improvement of blood, immunological and radiological parameters; and reduced recovery times (17-19). The Medical Subject Heading database at PubMed contains more than 7,000 articles on laser therapy.

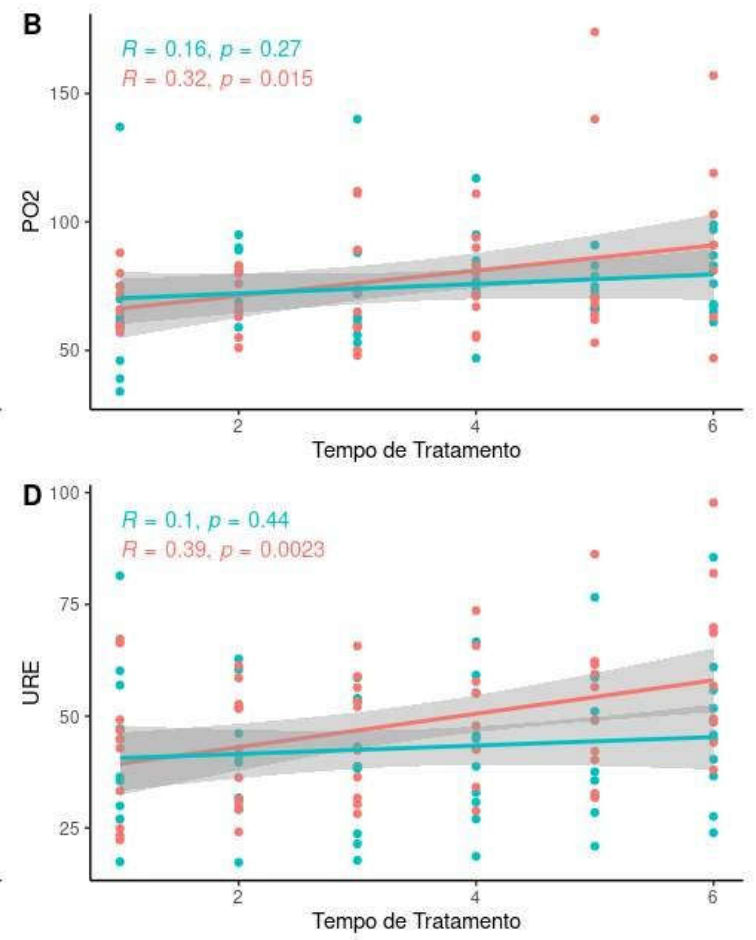

Figure 3 - Data dispersion, with the line representing the linear model and the gray area the model's confidence interval. A) Reactive Protein C B) Oxygen partial pressure C) Platelets D) Urea. The $\mathrm{X}$-axis represents the time in days since the beginning of the treatment and the $\mathrm{Y}$-axis represents the observed values of the parameter. The blue color represents the control group and the red color the lasergroup

\section{DISCUSSION}

The initial mean of the CRP marker in the patients in the group was approximately $160 \%$ higher than in the control group, indicating greater complexity in the cases of the laser group, a value above the average of critical cases, while the mean of the control group would be classified as a severe case but not as a critic (12). Despite the higher levels of the PCR marker in the laser group than the control group, we can observe an increase in $\mathrm{PO} 2$ in the group that received laser treatment, showing a positive correlation with the intervention time. In a situation of global pandemic, where several countries experience an overload of health systems (high levels of bed occupancy and lack of ventilatory equipment), and in some cases even lacking compressed oxygen for patients, as seen in the State of Amazonas in Brazil, laser therapy can be a short-term therapeutic option that is simple to implement (low cost and little labor) (13). The reduction in the number of platelets in the blood is a phenomenon observed in patients with covid-19, this reduction being more evident in patients with more severe cases (14). The platelet count was lower in the patients in the laser group, which was expected considering the greater inflammation indicated by the CRP level. Despite this lower initial number, the final average of the laser group ended up being higher than that of the control group, indicating a better evolution of this parameter in the group that received the treatment. In both groups, an increase in the level of urea in the patients can be observed. This increase may occur due to water reabsorption (passive reabsorption of urea) due to systemic inflammation, or the activation of the renin-angiotensin-aldosterone system, and the peak in the final stage of the laser group can be associated with the highest level of $\mathrm{CRP}$, that is, the water reabsorption process (and passive urea reabsorption) was more intense $(15,16)$. Laser therapy has been used in diseases of the respiratory tract since 1978 .
Its effects have been confirmed by several meta-analysis studies and include anti-inflammatory and analgesic effects, tissue healing, treatment of tendinopathy and improvement of lymphedema, increased protein production and cell proliferation, accelerated healing, and cell regeneration, among others (20-25). The effects of laser therapy are not due to heat, but to a photochemical reaction that occurs when a photoreceptor molecule within the cell absorbs a photon of light, becomes activated, and changes the permeability and metabolism of the cell membrane. Cytochrome $\mathrm{C}$ oxidase, opsins, and their associated calcium channels are the main mediators of photochemical mechanisms (11). As an answer, we have increased mRNA synthesis and cell proliferation. Laser therapy produces reactive oxygen species (ROS) in normal cells, but ROS levels are reduced when it is used in cells with oxidative stress (11). In the treatment of COVID-19, laser therapy is effective against the cytokine storm involved in the pathophysiology of Acute Respiratory Discomfort Syndrome (ARDS) while promoting tissue healing and regeneration. Experimental and animal models of lung disease and infection have revealed multiple cellular and molecular effects, which are local and systemic. Laser therapy reduces inflammation without impairing lung function in acute lung injuries, significantly reduces the number of inflammatory cells and pro-inflammatory cytokines such as interleukin 1B, interleukin 6, TNF-alpha, decreases collagen deposition, and increases interleukin expression 10, making promising therapy for chronic obstructive pulmonary disease. The major mechanisms responsible for modulating the inflammatory process involve increased microcirculation, angiogenesis, and immune cell modulation (26). In a model of pulmonary inflammation, a decrease in the number of leukocytes, a decrease in mast cell degranulation and pulmonary microcirculatory permeability, and the release of inflammatory cytokines have been demonstrated (27). 
Aimbire and colleagues showed that laser therapy restores the capacity for bronchial relaxation by increasing cyclic AMP, and decreases bronchial hyperreactivity by controlling calcium sensitivity and increasing the production of interleukin 10 messenger RNA, with anti-inflammatory action. (28). There is also evidence of an improvement in lung function through photobiomodulation in a model of idiopathic pulmonary fibrosis (29), reduction in both cholinergic hyper-reactivity and expression of TNF alpha messenger RNA via INFKb (30). We started with a small sample size $(\mathrm{N}=20)$ due to the state of the pandemic that we are experiencing, which makes large sampling and application methods unfeasible, which would require a time window not available at this time. The results demonstrate the potential of using laser as a therapeutic alternative, highlighting the need for further study. According to the sample size analysis, considering the Brazilian population, approximately 400 samples would be needed to have a $95 \%$ confidence level, and 700 samples to have a $99 \%$ confidence level.

\section{CONCLUSION}

Therefore, when thinking about intervening in the pathophysiology of the disease, one should take into account the use of techniques or drugs that can act both in restricting the most pernicious phase of the inflammatory cascade and in modulating all events related to the evolution of COVID- 19. And in this last aspect, laser therapy can be a viable option since its effectiveness has been demonstrated in several other diseases with similar inflammatory events, and the improvement of physiological parameters, even in the most critical cases of the disease.

\section{Acknowledgments}

The present study did not have external funding. All costs with equipment, application and data collection, statistical analysis, text formatting, and sending for publication, were borne by the authors.

\section{REFERENCES}

Aimbire F, de Lima FM, Costa MS, Albertini R, Correa JC, Iversen $\mathrm{VV}$, et al. Effect of low level laser therapy on bronchial hyperresponsiveness. Lasers Med Sci. $1^{\circ}$ de julho de 2009;24(4):56776.

Aimbire F, Ligeiro de Oliveira AP, Albertini R, Corrêa JC, Ladeira de Campos CB, Lyon JP, et al. Low level laser therapy (LLLT) decreases pulmonary microvascular leakage, neutrophil influx and IL-1beta levels in airway and lung from rat subjected to LPS-induced inflammation. Inflammation. junho de 2008;31(3):189-97.

Amirov NB. Parameters of membrane permeability, microcirculation, external respiration, and trace element levels in the drug-laser treatment of pneumonia. Ter Arkh. 2002;74(3):40-3.

Bjordal JM, Lopes-Martins RAB, Joensen J, Iversen VV. The antiinflammatory mechanism of low level laser therapy and its relevance for clinical use in physiotherapy. Phys Ther Rev. $1^{\circ}$ de agosto de 2010;15(4):286-93.

Cheng A, Hu L, Wang Y, Huang L, Zhao L, Zhang C, et al. Diagnostic performance of initial blood urea nitrogen combined with D-dimer levels for predicting in-hospital mortality in COVID-19 patients. Int J Antimicrob Agents. $1^{\circ}$ de setembro de 2020;56(3):106110.

da Cunha Moraes G, Vitoretti LB, de Brito AA, Alves CE, de Oliveira NCR, dos Santos Dias A, et al. Low-Level Laser Therapy Reduces Lung Inflammation in an Experimental Model of Chronic Obstructive Pulmonary Disease Involving P2X7 Receptor. Oxid Med Cell Longev. 4 de março de 2018;2018:e6798238.

de Lima FM, Villaverde AB, Albertini R, de Oliveira APL, Faria Neto HCC, Aimbire F. Low-level laser therapy associated to Nacetylcysteine lowers macrophage inflammatory protein-2 (MIP2) mRNA expression and generation of intracellular reactive oxygen species in alveolar macrophages. Photomed Laser Surg. dezembro de 2010;28(6):763-71.

Derbenev VA, Mikhailov VA, Denisov IN. Use of low-level laser therapy (LLLT) in the treatment of some pulmonary diseases: ten-year experience. In: Laser Florence '99: A Window on the Laser Medicine World [Internet]. International Society for Optics and Photonics; 2000 [citado 15 de março de 2021]. p. 323-5. Disponível em: https://www.spiedigitallibrary.org/conference-proceedings-ofspie/4166/0000/Use-of- low-level-laser-therapy-LLLT-in-thetreatment/10.1117/12.389506.short

Erkinovna TB, Tulkunovna MH. Efficacy of laser therapy in infants with infectious-inflammatory respiratory diseases. Eur Sci Rev [Internet]. 2016 [citado 15 de março de 2021];(1-2). Disponível em: https://cyberleninka.ru/article/n/efficacy-of-laser- therapyin-infants-with-infectious-inflammatory-respiratory-diseases

Gorbalenya AE, Baker SC, Baric RS, de Groot RJ, Drosten C, Gulyaeva AA, et al. The species Severe acute respiratory syndrome-related coronavirus: classifying 2019-nCoV and naming it SARS-CoV-2. Nat Microbiol. abril de 2020;5(4):53644.

Hamblin MR. Mechanisms and applications of the anti-inflammatory effects of photobiomodulation. AIMS Biophys. 2017;4(3):33761.

Huang C, Wang Y, Li X, Ren L, Zhao J, Hu Y, et al. Clinical features of patients infected with 2019 novel coronavirus in Wuhan, China. The Lancet. 15 de fevereiro de 2020;395(10223):497506.

Jang H, Lee H. Meta-analysis of pain relief effects by laser irradiation on joint areas. Photomed Laser Surg. agosto de 2012;30(8):40517.

Kazem Shakouri S, Soleimanpour J, Salekzamani Y, Oskuie MR. Effect of low-level laser therapy on the fracture healing process. Lasers Med Sci. 28 de abril de 2009;25(1):73.

Medical oxygen crisis: a belated COVID-19 response - The Lancet [Internet]. [citado 15 de março de 2021]. Disponível em: https://www.thelancet.com/journals/lancet/article/PIIS01406736(21)00561-4/fulltext

Miranda da Silva C, Peres Leal M, Brochetti RA, Braga T, Vitoretti LB, Saraiva Câmara NO, et al. Low Level Laser Therapy Reduces the Development of Lung Inflammation Induced by Formaldehyde Exposure. PLoS ONE [Internet]. 16 de novembro de 2015 [citado 15 de março de 2021];10(11). Disponível em: https://www.ncbi.nlm.nih.gov/pmc/articles/PMC4646654/

Ostronosova NS. Outpatient use of laser therapy in bronchial asthma. Ter Arkh. 2006;78(3):41-4.

Pereira NL, Ahmad F, Byku M, Cummins NW, Morris AA, Owens A, et al. COVID-19: Understanding Inter-Individual Variability and Implications for Precision Medicine. Mayo Clin Proc. $1^{\circ}$ de fevereiro de 2021;96(2):446-63.

Rigonato-Oliveira NC, Brito AA, Moraes G, Soares C, Aquino-Junior JC, Vitoretti LB, et al. Effect of low level laser therapy in a model of pulmonary idiopathic fibrosis. Eur Respir J [Internet]. $1^{\circ}$ de setembro de 2015 [citado 15 de março de 2021];46(suppl 59). Disponível em: https://erj.ersjournals.com/ content/46/suppl 59/PA945

Smoot B, Chiavola-Lärson L, Lee J, Manibusan H, Allen DD. Effect of low- level laser therapy on pain and swelling in women with breast cancer-related lymphedema: a systematic review and meta-analysis. J Cancer Surviv Res Pract. junho de 2015;9(2):287-304.

Sparks MA, Crowley SD, Gurley SB, Mirotsou M, Coffman TM. Classical Renin-Angiotensin System in Kidney Physiology. Compr Physiol. julho de 2014;4(3):1201-28.

Sterne JAC, Diaz J, Villar J, Murthy S, Slutsky AS, Perner A, et al. Corticosteroid therapy for critically ill patients with COVID-19: A structured summary of a study protocol for a prospective meta-analysis of randomized trials. Trials. 24 de agosto de 2020;21(1):734.

Tan L, Wang Q, Zhang D, Ding J, Huang Q, Tang Y-Q, et al. Lymphopenia predicts disease severity of COVID-19: a 
descriptive and predictive study. Signal Transduct Target Ther. 27 de março de 2020;5(1):1-3.

Tavakolpour S, Rakhshandehroo T, Wei EX, Rashidian M. Lymphopenia during the COVID-19 infection: What it shows and what can be learned. Immunol Lett. setembro de 2020;225:31-2.

Torri S, Weber JBB. Influence of Low-Level Laser Therapy on the Rate of Orthodontic Movement: A Literature Review. Photomed Laser Surg. 24 de julho de 2013;31(9):411-21.

Tumilty S, Munn J, McDonough S, Hurley DA, Basford JR, Baxter GD. Low level laser treatment of tendinopathy: a systematic review with meta-analysis. Photomed Laser Surg. fevereiro de 2010;28(1):3-16.
Wang L. C-reactive protein levels in the early stage of COVID-19. Médecine Mal Infect. $1^{\circ}$ de junho de 2020;50(4):332-4.

WHO Coronavirus (COVID-19) Dashboard [Internet]. [citado 15 de março de 2021]. Disponível em: https://covid19.who.int

Woodruff LD, Bounkeo JM, Brannon WM, Dawes KS, Barham CD, Waddell DL, et al. The efficacy of laser therapy in wound repair: a meta-analysis of the literature. Photomed Laser Surg. junho de 2004;22(3):241-7.

Wool GD, Miller JL. The Impact of COVID-19 Disease on Platelets and Coagulation. Pathobiology. 2021;88(1):15-27. 